PROSTATITIS

\section{Whither "chronic prostatitis"?}

\section{G A Luzzi}

\section{For many men, time, rather than current treatments, may have the greatest influence on symptoms}

In is nearly a decade since the National Institutes of Health (NIH) sponsored international consensus conference on chronic prostatitis led to the development of a productive multicentre collaboration in North America (Chronic Prostatitis Collaborative Research Network) and stimulated research initiatives around the world. ${ }^{1}$ A modified classification for prostatitis was proposed, with a new name and clinical definition for the largest category, chronic pelvic pain syndrome (CPPS), to replace chronic non-bacterial prostatitis and prostatodynia. $^{2}$ Subsequently, development of a validated Chronic Prostatitis Symptom Index (NIH-CPSI) provided an outcome measure for treatment trials that is now almost universally adopted and allows comparison between studies. ${ }^{3}$ Although not intended to be a diagnostic instrument, and therefore requiring caution in its use as a means of detecting the condition, numerous studies using the same instrument have suggested a high population prevalence of CPPS. $^{4}$

Significant advances have been made in our understanding of the prevalence and impact of this condition, its natural history, and to some extent, the pathogenesis, although the aetiology remains a mystery and advances in therapy have been disappointing. Nearly 10 years on, the time has come for greater clarity in our diagnostic labelling and a frank acceptance of the limitations of historical diagnostic approaches. The time has come to drop the term "chronic prostatitis" and to avoid misleading and imprecise use of "prostatitis" (box).
The NIH classification signalled a conceptual shift in approach, and its four categories (acute bacterial prostatitis, chronic bacterial prostatitis, CPPS, and asymptomatic inflammatory prostatitis) are distinct entities. It now becomes arguable whether these conditions should feature in the same classification. Use of the unvalidated four glass test in diagnosis and classification led to confusion; recent work confirmed that results do not correlate with symptoms, and white cells in expressed prostatic secretions are a regular feature in symptomless controls. ${ }^{56}$ This adds to the evidence for lack of clinical value in subclassifying CPPS into inflammatory and non-inflammatory categories.

In the light of developments, the current classification should, logically, be dismantled, and a greater focus placed on each of its components. In particular, CPPS (NIH category III) may encompass a heterogeneous group of causes of chronic genital or pelvic pain. Better understanding of the aetiology or aetiologies will be essential for development of reliable diagnostic techniques and effective treatment.

In theory, CPPS may be caused by bladder, pelvic floor, prostate, or seminal vesicle pathology. Urodynamic studies suggested a neuromuscular basis for CPPS (pelvic floor or bladder neck dysfunction) that provided the rationale for treatment with $\alpha$ blockers. ${ }^{7}$ Current interest is focused on explaining observed elevations in proinflammatory cytokines in the genital tract in men with CPPS, ${ }^{8}$ especially infective triggers, autoimmunity, or neurogenic

Modernisation of chronic prostatitis

- The loosely applied terms "prostatitis" and "chronic prostatitis" should no longer be used.

- Diagnosis of chronic bacterial prostatitis should be confined to men with recurrent urinary tract infection in whom a prostatic focus of infection is suspected.

- Genital or pelvic pain is required for the diagnosis of CPPS.

- The four glass test should be confined to research contexts in which the test itself is being evaluated.

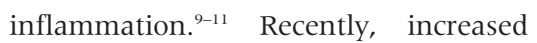
perineal pain sensitisation was reported in men with CPPS. ${ }^{12}$

CPPS also has the features of a somatoform disorder. ${ }^{13}$ Despite the high prevalence of this condition, which is regularly seen by GPs, urologists, and genitourinary physicians, a recent review did not include CPPS in a long list of functional somatic syndromes by specialty (although chronic pelvic pain in women was included). ${ }^{14}$

Treatment of the condition remains frustrating. We have a clearer picture of what doesn't work or should no longer be used, such as very prolonged courses of antibiotics. Otherwise, none of the treatments used is supported by good evidence. This position hasn't improved much since publication of a systematic review in 2000, ${ }^{15}$ except that recent small controlled trials have strengthened the case for $\alpha$ blockers (such as tamsulosin) in severe CPPS. ${ }^{16}{ }^{17}$ The range of other possible therapies under recent evaluation remains unfocused, and includes anti-inflammatory approaches (cyclooxygenase-2 selective inhibitors; corticosteroids), "phytotherapy" (quercetin), hormonal methods (finasteride; mepartricin), physical therapies (electrostimulation; transurethral needle ablation), complementary therapies (acupuncture), and biofeedback. ${ }^{18-26}$

Controlled studies examining possible psychological factors reported elevated scores for depression, anxiety, and somatisation in men with CPPS..$^{27}$ In one study, more intense patterns of psychological distress were demonstrated in approximately $40 \%$ of men, many of whom were depressed. ${ }^{28}$ This highlighted the need to consider undiagnosed depression and anxiety states in men presenting with severe refractory CPPS, and the importance of evaluating mental health interventions.

In this issue of STI ( $p$ 147), Lee and colleagues report interesting preliminary findings from their trial of the antidepressant sertraline, a selective serotonin reuptake inhibitor (SSRI), in men with CPPS. Improvement in symptoms was demonstrated for sertraline $50 \mathrm{mg}$ daily taken for 13 weeks. However, it would be premature to recommend use of sertraline in men with CPPS on the basis of the study, because of failure to reach significance in the placebo controlled substudy (possibly owing to small numbers and lack of power) and use of a symptom index that predates the NIH-CPSI. Concerns about possible suicide risk associated with SSRIs might also be a barrier in their use, although the risk seems linked to depression rather than a separate drug effect. ${ }^{29}$ SSRIs might influence symptoms in CPPS by treating underlying depression 
or because of known analgesic effects. In the small sample studied by Lee et al, baseline assessment did not detect significant depression; how effective treatment would be in a larger, more representative, group of patients with CPPS-in whom depression may be a more prominent feature-remains to be determined. Recruitment into adequately powered trials is likely to require a multicentre collaboration.

For many men, time, rather than current treatments, may have the greatest influence on symptoms, with around one third reporting resolution of symptoms after 1 year. ${ }^{30}$ Overall management of CPPS (investigation and treatment) remains highly variable, ${ }^{31}$ and access to the most appropriate therapists (including pain experts, psychotherapists and, possibly, psychosexual therapists and physiotherapists) is often inadequate. The extent to which genitourinary medicine clinics can develop services for chronic conditions (other than HIV) may be limited by the strengthened focus on sexually acquired infections driven by epidemiological trends and the national sexual health strategy. At this point, the future for improving service provision for men with this often distressing and disabling condition seems very uncertain.

Sex Transm Infect 2005;81:96-97.

doi: $10.1136 /$ sti.2004.012310

Correspondence to: G A Luzzi, Department of Genitourinary Medicine, Wycombe Hospital, High Wycombe HP1 1 2TT, UK; luzg@wycgu. demon.co.uk

\section{REFERENCES}

1 NIH Workshop on Chronic Prostatitis. Executive summary. (www.niddk.nih.gov./health/urolog/ pubs/cpwork/cpwork.htm). Bethesda, MD:

National Institutes of Health-National Institute of
Diabetes and Digestive and Kidney Diseases, 1995; appendix 1:1-5. (www.niddk.nih.gov.) health/urolog/pubs/cpwork/cpwork.htm).

2 Krieger JN, Nyberg J, Nickel JC. NIH consensus definition and classification of prostatitis. JAMA 1999;282:236-7.

3 Litwin MS, McNaughton Collins M, Fowler FJ, et al. The National Institutes of Health chronic prostatitis symptom index: development and validation of a new outcome measure. J Urol validation of a new

4 Krieger JN, Riley DE, Cheah PY, et al. Epidemiology of prostatitis: new evidence for a worldwide problem. World J Urol 2003;21:70-4.

5 Schaeffer AJ, Knauss JS, Landis JR, et al. Leukocyte and bacterial counts do not correlate with severity of symptoms in men with chronic prostatitis: the National Institutes of Health Chronic Prostatitis Cohort Study. J Urol 2002;168:1048-53.

6 Nickel JC, Alexander RB, Schaeffer AJ, et al. Leukocytes and bacteria in men with chronic prostatitis/chronic pelvic pain syndrome compared to asymptomatic controls. J Urol 2003; 170:818-22.

7 Hellstrom WJG, Schmidt RA, Lue TF, et al. Neuromuscular dysfunction in nonbacterial prostatitis. Urology 1987;30:183-7.

8 Jang TL, Schaeffer AJ. The role of cytokines in prostatitis. World J Urol 2003;21:95-9.

9 Krieger JN, Riley DE. Bacteria in the chronic prostatitis-chronic pelvic pain syndrome: molecular approaches to critical research questions. J Urol 2002; 167:2574-83.

10 Batstone GRD, Doble A, Gaston JSH. Autoimmune T cell responses to seminal plasma in chronic pelvc pain syndrome (CPPS). Clin Exp Immunol 2002;128:302-7.

11 Wesselman U. Neurogenic inflammation and chronic pelvic pain. World J Urol 2001;19:180-5.

12 Yang CC, Lee JC, Kromm BG, et al. Pain sensitization in male chronic pelvic pain syndrome: why are symptoms so difficult to treat? $J$ Urol 2003; 170:823-6.

13 Ehlert U, Heim C, Hellhammer. Chronic pelvic pain as a somatoform disorder. Psychother Psychosom 1999:68:87-94.

14 Wessely S, Nimnuan C, Sharpe M. Functional somatic syndromes: one or many? Lancet 1999:354:936-9.

15 McNaughton Collins M, MacDonald R, Wilt TJ. Diagnosis and treatment of chronic abacterial prostatitis: a systematic review. Ann Intern Med 2000;133:367-81.

16 Nickel JC, Narayan P, McKay J, et al. Treatment of chronic prostatitis/chronic pelvic pain syndrome with tamsulosin: a randomized double blind trial. J Urol 2004;171:1594-7

17 Mehik A, Alas P, Nickel JC, et al. Alfuzosin treatment for chronic prostatitis/chronic pelvic pain syndrome: a prospective, randomised double-blind, placebo-controlled pilot study Urology 2003;62:425-9.

18 Nickel JC, Pontari M, Moon T, et al. A randomized, placebo controlled, multicenter study to evaluate the safety and efficacy of rofecoxib in the treatment of chronic nonbacterial prostatitis. J Urol 2003;169:1401-5.

19 Dimitrakov JD, Tchitalov J, Dikov D. Efficacy and safety of corticosteroids in the treatment of $\mathrm{CP}$ / CPPS: a randomized, double-blind, placebocontrolled trial (abstract). J Urol 2004;171(Suppl):S61-2.

20 Shoskes DA, Zeitlin SI, Shahed A, et al. Quercetin in men with category III chronic prostatitis: a preliminary prospective double-blind, placebocontrolled trial. Urology 1999;54:960-3.

21 Nickel JC, Downey J, Pontari MA, et al. A randomized placebo-controlled multicentre study to evaluate the safety and efficacy of finasteride for male chronic pelvic pain syndrome (category IIIA chronic nonbacterial prostatitis). BJU Int 2004;93:991-5

22 De Rose AF, Gallo F, Giglio M, et al. Role of mepartricin in category III chronic nonbacterial prostatitis/chronic pelvic pain syndrome: a randomized prospective placebo-controlled trial. Urology 2004:63:13-16.

23 John H, Ruedi C, Kotting S, et al. A new high frequency electrostimulation device to treat chronic prostatitis. J Urol 2003;170:1275-7.

24 Giannakopoulos X, Entezari K, Schulman C, et al. Transurethral needle ablation for chronic nonbacterial prostatitis: a 3-year follow-up study (abstract). J Urol 2004;171(Suppl):S62.

25 Chen R, Nickel JC. Acupuncture ameliorates symptoms in men with chronic prostatitis chronic pelvic pain syndrome. Urology 2003;61:1156-9.

26 Cornel EB, van Haarst EP. Chronic pelvic pain syndrome type 3 successfully treated with biofeedback physical therapy. J Urol 2004;171(Suppl):S30.

27 De la Rosette JJMCH, Ruijgrok MCM, Jeuken JMG, et al. Personality variables involved in chronic prostatitis. Urology 1993;42:654-62.

28 Berghuis JP, Heiman JR, Rothman I, et al. Psychological and physical factors involved in chronic idiopathic prostatitis. J Psychosom Res 1996:41:313-25.

29 Jick H, Kaye JA, Jick SS. Antidepressants and the risk of suicidal behaviors. JAMA 2004;292:338-43

30 Nickel JC, Downey JA, Nickel K, et al. Prostatitislike symptoms: one year later. BJU Int 2002:90:678-81.

31 Luzzi GA, Bignell C, Mandal D, et al. Chronic prostatitis/chronic pelvic pain syndrome: national survey of Genitourinary Medicine clinics. Int J STD AIDS 2002;13:416-19.

\section{Lymphogranuloma venereum in the United Kingdom}

\section{P French, C A Ison, N Macdonald}

\section{First cases reported from enhanced surveillance}

U til 2003 lymphogranuloma venereum (LGV), a disease caused by the more invasive $\mathrm{L}$ serovars of Chlamydia trachomatis, was considered a rare disease outside resource poor countries. Since then it has emerged as a significant problem among men who have sex with men (MSM) in Europe. In 2003 an outbreak of LGV was recognised in Rotterdam in the Netherlands. ${ }^{1}$ More than 100 men have been reported in this outbreak, most of whom were HIV positive and many had concomitant sexually transmitted infec- tions including hepatitis C infection. Although many reported unprotected anal sex as a risk factor for acquisition of LGV, fisting and the sharing of sex toys also appeared as possible routes of transmission. Almost all presented with proctitis and symptoms included rectal pain, discharge, tenesmus, and other signs of lower gastrointestinal inflammation including constipation and abdominal pain. Some reported systemic symptoms such as fever and malaise. Genital and inguinal symptoms were rare with only one patient presenting with inguinal lymphadenopathy.

Since that report similar outbreaks have been recognised in Antwerp, Hamburg, and Paris..$^{2-4}$ Cases have also been reported from Sweden and more recently from the United States (New York, San Francisco, and Atlanta). ${ }^{5}$ All 
the reported cases have been caused by the L2 serovar, although there is some evidence that a number of genetically distinct strains of $C$ trachomatis $\mathrm{L} 2$ are responsible for these outbreaks. ${ }^{6}$

In October 2004 the Health Protection Agency (HPA) sent out an alert to genitourinary medicine (GUM) clinicians in England and established a case definition, reference service, and reporting system for LGV. ${ }^{7}$ In addition to the information produced by the HPA, the Terence Higgins Trust produced briefings for use in clinics and a leaflet for use in gay venues to increase awareness. The case definition used by the HPA is confirmation of $C$ trachomatis and presence of an LGV serovar, L1, L2, or L3, by genotyping. The HPA reference service will test rectal specimens from patients with anorectal symptoms (typically proctitis, rectal discharge) or urethral specimens from patients with inguinal lymphadenopathy that are known to be positive for $C$ trachomatis. Serology for $C$ trachomatis has been used in Europe and can suggest the possibility of LGV, but does not confirm cases because of a lack of specificity, and has not been used in England as part of the case definition (www.hpa.org.uk/ infections/topics_az/hiv_and_sti/LGV/lgv. htm).

In January 2005 the first 24 cases of LGV were reported in the United Kingdom, ${ }^{89}$ most from London clinics. Enhanced surveillance data were available for 19 cases and confirmed a picture similar to that reported in the rest of Europe. All were MSM, 17 were HIV positive, four also had hepatitis C infection, and most had symptoms suggesting LGV. Fifteen patients reported a probable country of infection; five in mainland Europe and 10 in the United Kingdom. Up to the middle of February 2005 a total of 34 cases of LGV have been reported in the United Kingdom.

LGV presenting as proctitis in homosexual men is well recognised. ${ }^{10}$ The primary (papule/ulcer) of LGV frequently goes unnoticed and patients often present with acute haemorrhagic proctitis and may have pronounced systemic symptoms such as fever and weight loss. Proctoscopy often reveals marked proctitis, which is usually confined to the distal $10 \mathrm{~cm}$ of the anorectal canal. Left untreated, chronic inflammation may lead to stricture and fistula formation as well as local lymphatic obstruction and lymphoedema. ${ }^{11}$ Patients with acute proctitis related to LGV usually respond well to antibiotic therapy. At present the recommended treatment for LGV in the United Kingdom is either oral doxycycline $100 \mathrm{mg}$ twice daily, or oral erythromycin $500 \mathrm{mg}$ four times a day, both regimens given for 3 weeks. ${ }^{12}$ Patients with chronic infection including abscess, fistulas, and strictures often require surgical intervention.

It is likely that LGV has been present for some time in MSM in the United Kingdom, with many cases going undiagnosed. The first UK case identified so far is from a retrospective sample dating from January 2004. The epidemiology and clinical features of LGV in MSM are not fully understood; it is likely that some undiagnosed cases will have progressed to invasive disease, while others may yet prove to be asymptomatic. Clearly, further collaborative research is required.

The first steps in understanding and controlling this outbreak are to increase community and clinician awareness of LGV, to further develop our surveillance system and to monitor clinical manifestations. A national incident team has been established to oversee responses with the aim of developing effective control measures for this outbreak. The key challenge will be to identify and implement appropriate health promotion and prevention measures, particularly addressing the sexual health needs of HIV positive homosexual men, and ensure that potentially severe sequelae of untreated LGV are minimised.

Sex Transm Infect 2005;81:97-98.

doi: $10.1136 /$ sti.2005.015263

\section{Authors' affiliations}

P French, Mortimer Market Centre, Mortimer Market, and Camden Primary Care Trust and University College London, UK

C A Ison, N Macdonald, Health Protection Agency Centre for Infections, 61 Colindale Avenue, London NW9 5HT, UK
Correspondence to: Patrick French, Mortimer Market Centre, London, UK; PFrench@ gum.ucl.ac.uk

A national LGV incident group has been established by the HPA in collaboration with the British Society for Sexual Health and HIV (BASHH), the Terence Higgins Trust (THT), and the Society for Sexual Health Advisers (SHAA) and is chaired by Helen Ward (helen.ward@ hpa.org.uk).

Leaflet produced by Terence Higgins Trust. (Single copies can be obtained through THT Direct 08451221 200; multiple copies by emailing james.glavin@tht.org.uk).

\section{REFERENCES}

1 Götz H, Nieuwenhuis R, Ossewaarde T, et al Preliminary report of an outbreak of

lymphogranuloma venereum in homosexual men in the Netherlands, with implications for other countries in western Europe. Eurosurveillance Weekly 2004:8(4):22 Jan 2004

2 Vandenbruaene M. Uitbraak van Lymphogranuloma Venereum in Antwepen en Rotterdam. Epidemiologisch Bulletin van de Vlaamse Gemeenschap 2004;47:4-6.

3 Robert Koch-Institut. Zum gehäuften Auftreten von Lymphogranuloma Venereum in Hamburg im Jahr 2003. Epidemiologisches Bulletin 2004; 25: 18 June 2004.

4 Institut de Veille Sanitaire. Emergence de la Lymphogranulomatose vénérienne rectale en France:cas estimés au 31 mars 2004. Synthése réalisée le ler Juin, 2004.

5 New York City Department of Health and Mental Hygiene. Two New York City residents diagnosed with rare sexually transmitted infection; same strain found in Europe. Press release, 2 February 2005 (available on www.nyc.gov/html/doh/ $\mathrm{html} /$ public/press05/pr011-05.html)

6 Meyer T, Arndt R, von Krosigk A, et al. Repeated detection of lymphogranuloma venereum caused by Chlamydia trachomatis $L 2$ in homosexual men in Hamburg (letter). Sex Transm Infect 2005;81:91-4.

7 Health Protection Agency. Enhanced surveillance of lymphogranuloma venereum (LGV) in England. Commun Dis Rep CDR Wkly [serial online] 2004;14(41): News (available at / www.hpa.org uk/cdr/PDFfiles/2004/cdr4104.pdf).

8 Health Protection Agency. Initial results of enhanced surveillance for lymphogranuloma venereum (LGV) in England Commun Dis Rep CDR Wkly [serial online] 2005;15(5): News (available at www.hpa.org.uk/cdr/archives/ archive05/News/news0405.htm\#botulism).

9 Macdonald N, Ison C, Martin I, et al. Initial results of enhanced surveillance for lymphogranuloma venereum (LGV) in England. Eurosurveillance $2005 ; 10: 20$. January 2005 (available at www. eurosurveillance.org/ew/2005/050127.asp).

10 Quinn TC, Goodall SE, Mrtichian E, et al. Chlamydia trachomatis proctitis. N Engl J Med 1981;305:195-200.

11 Mabey D. Peeling. Lymphogranuloma venereum. Sex Transm Infect 2002;78:90-2.

12 Clinical Effectiveness Group. National guideline for the management of lymphogranuloma venereum. Sex Transm Infect 1999;75(Supp1 1):S40-2. 